\title{
Analysis on Groundwater Dynamic Characteristics and Causes in Yao Ba Oasis
}

\author{
Li Huan-huan, Lu Yu-dong, Zhang Xiao-zhou, Zheng Ce \\ School of Environmental Science and Engineering, Chang'an University, Xi'an, China

\section{Email address:} \\ 17742499497@163.com (Li Huanhuan), luyudongphd@163.com (Lu Yudong), zhang29060926@163.com (Zhang Xiaozhou), \\ 459922848@qq.com (Zheng Ce)
}

\section{To cite this article:}

Li Huan-huan, Lu Yu-dong, Zhang Xiao-zhou, Zheng Ce. Analysis on Groundwater Dynamic Characteristics and Causes in Yao Ba Oasis. Earth Sciences. Vol. 4, No. 6, 2015, pp. 241-246. doi: 10.11648/j.earth.20150406.14

\begin{abstract}
According to the monitoring data from 1984 to 2014 of the groundwater table in Yao Ba oasis, Alax League, Inner Mongolia of China, analysis the annual and interannual variation of the groundwater table and its genesis in the irrigation area. In addition, use the Surfer11 to draw the water-table contour and restore the cone of depression. Analytical results show that the dynamic type in the irrigation area is artificial exploitation type. Groundwater exploitation is a major factor causing the groundwater table dynamic change, the groundwater table characteristics and the cone of depression mainly depend on the size of exploitation.
\end{abstract}

Keywords: Groundwater Table, Dynamic Characteristics, Cause Analysis, Cone of Depression, Yao Ba Oasis

\section{腰坝绿洲地下水位动态特征及成因分析}

\author{
李环环, 卢玉东, 张晓周, 郑策 \\ 环境科学与工程学院, 长安大学, 西安, 中国 \\ 邮箱 \\ 17742499497@163. com(李环环), luyudongphd@163.com(卢玉东), zhang29060926@163.com(张晓周), 459922848@qq. com(郑策) \\ 摘要：根据中国内蒙古自治区阿拉善盟腰坝绿洲1981 2014年的地下水位监测数据，分析灌区地下水位年内、年际动 \\ 态变化特征及影响因素, 并利用Surfer11绘制出地下水等水位线, 还原降落漏斗形成与发展的过程。分析结果表明: \\ 腰坝灌区地下水位动态类型为人工开采型。开采地下水是地下水位动态变化的主要因素, 地下水位特征以及降落漏斗 \\ 的复杂形态主要取决于开采量的大小。
}

关键词：地下水位，动态特征，成因分析，降落漏斗，腰坝绿洲

\section{1. 引言}

阿拉善盟位于中国内蒙古自治区的最西部 ${ }^{[1]}$, 腾格里、 巴丹吉林、乌兰布和三大沙漠横贯阿拉善盟全境, 是典型 的干旱荒漠区。腰坝绿洲是阿拉善盟的十大绿洲之一，于 20 世纪70年代开始较大规模的移民开发, 人口不断增多, 耕地面积不断扩大, 需水量急剧增加。水资源问题一直是 腰坝地区倍受关注的问题, 水资源能否可持续利用, 直接
关系到腰坝地区能否永续发展。目前腰坝绿洲人口共 9283 人, 开发耕地 9 万多亩, 机电井 375 眼。由于当地没有河流 等地表水源, 加之年降雨量很小, 当地淡水资源主要依赖 地下水开采。灌区对地下水持续、大量的开采, 致使腰坝 成为阿拉善盟开发最早、面积最大、超采最严重的井灌区 ${ }^{[2]}$ 。水资源问题的日益加剧, 直接危及到当地的经济发展、 生态安全和人民生活。合理配置农业用水资源, 实现水资 源的可持续利用, 是现阶段腰坝绿洲亟需解决的问题。因 此, 分析灌区地下水位动态变化特征及影响因素, 为绿洲 
农业发展及政府政策的制定提供科学依据, 以实现腰坝绿 洲的可持续发展。

\section{2. 研究区概况}

\section{1. 自然地理条件}

腰坝绿洲东屏贺兰山, 西邻腾格里沙漠, 南距宁夏银 川市 $70 \mathrm{~km}$, 北至旗府巴彦浩特 $40 \mathrm{~km}$ 。行政区划隶属于中 国内蒙古自治区阿拉善左旗巴润别立镇。地理坐标为东经 $105^{\circ} 34^{\prime} \sim 105^{\circ} 39^{\prime}$, 北纬 $38^{\circ} 25^{\prime} \sim 38^{\circ} 36^{\prime}$ 。腰坝 绿洲面积约 $40 \mathrm{~km}^{2}$, 是阿拉善左旗的主要农牧区。研究区 巴润别立气象站1954 2012年观测资料显示, 该区多年平 均降水量为 $198 \mathrm{~mm}$, 降雨主要集中在 $7 \sim 9$ 月。多年平均蒸 发量为 $2394 \mathrm{~mm}$, 是平均降水量的 11.5 倍, 蒸发主要集中于 $4 \sim 9$ 月。多年平均气温为 $8.5^{\circ} \mathrm{C}$ 。年最高气温在 $6 \sim 8$ 月, 一般为 $23 \sim 25^{\circ} \mathrm{C}$; 年最低气温在 1 月份, 一般为 $-10^{\circ} \mathrm{C}$ 。气
候总体呈现为冬季严寒, 雨雪稀少; 夏季酷热, 蒸发强烈; 日照充足; 风大沙多 ${ }^{[3]}$ 。

\section{2. 水文地质条件}

腰坝地处贺兰山西麓洪积倾斜平原区, 地形东高西低, 高程在 $1290 \sim 1342 \mathrm{~m}$ 之间，为典型的东北南高而西低的半 环状地形。图1为灌区地形剖面图 ${ }^{[2]}$, 从图1中可以看出, 整个绿洲地区赋存多层结构的孔隙水及承压水。主要含水 岩组为第四系含水岩组和第三系含水岩组。第四系含水岩 组是井灌区供水的含水岩组, 其中第一含水组含水层累计 厚度 $10 \sim 30 \mathrm{~m}$, 为层间含水汇水层。第二含水组含水层累 计厚度 $20 \sim 40 \mathrm{~m}$; 第三系含水岩组埋深 200 多米，淡水资源 丰富 ${ }^{[4]}$ 。地下水类型主要为松散岩类孔隙水、碎屑岩类孔 隙及裂隙水、基岩裂隙水、碳酸盐岩裂隙溶洞水。地下水 的补给主要为贺兰山西麓洪水入渗补给和侧向地下径流 补给, 补给量大约为 2000 万 $\mathrm{m}^{3} /$ 年 $^{[5]}$ 。地下水的主要排泄方 式是人工排泄, 即平均布井的面状开采灌溉。

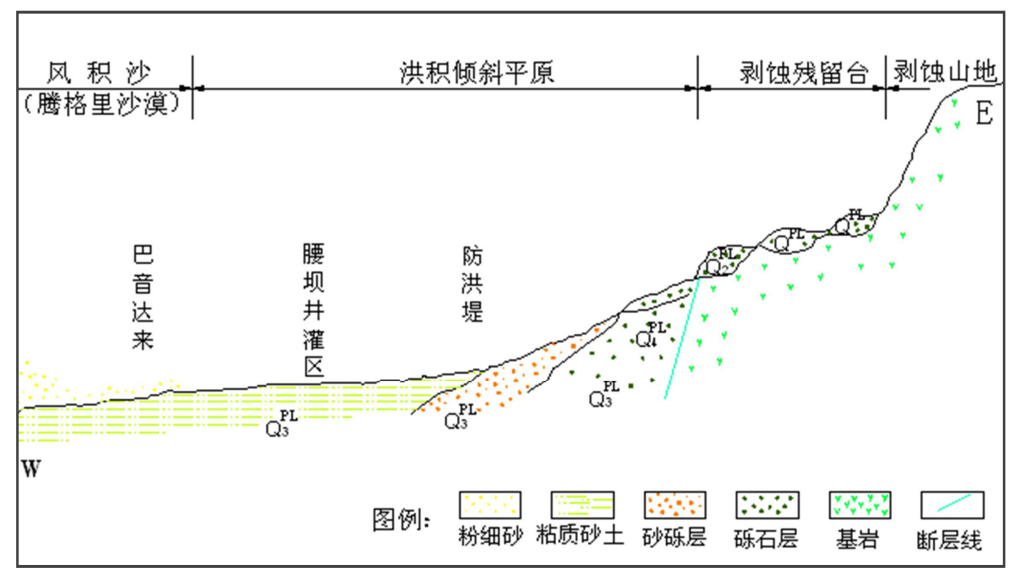

图1 腰坝灌区地形剖面图。

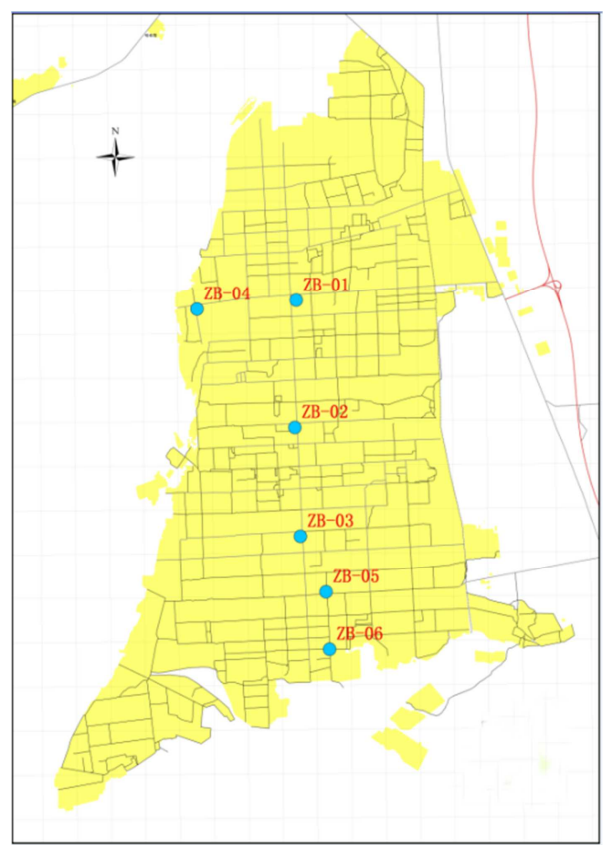

图2 腰坝灌区观测井分布位置图。

\section{3. 观测井介绍}

腰坝灌区地下水较大规模的开采始于 1970 年 ${ }^{[1]}$ 。地下 水动态观测网建于1979年。在1997年之前, 该观测网包括 13 口均匀分布在腰坝地区的地下水位观测井。2005年后, 整个腰坝地区仅剩下 6 口观测井, 分别为: ZB-01、ZB-02、 ZB-03、ZB-04、ZB-05、ZB-06。腰坝灌区观测井分布位置 见图2。

\section{3. 地下水位动态类型}

一般来说, 地下水位的变化通常受到水文、地质、气 象以及人为因素 (开采、补给) 等诸多因素的影响 ${ }^{[6]}$ 。以 ZB-02观测井为例, 由图3得知, 在降雨量最为丰富的 $6 、 7 、$ 8 月, 地下水位反而处于全年最低时期, 说明在腰坝地区 降水量对局部地区地下水的影响极其微弱。由图4可知, 地下水位的变化规律与开采量变化一致, 水位年内变化规 律主要与开采地下水有关。 


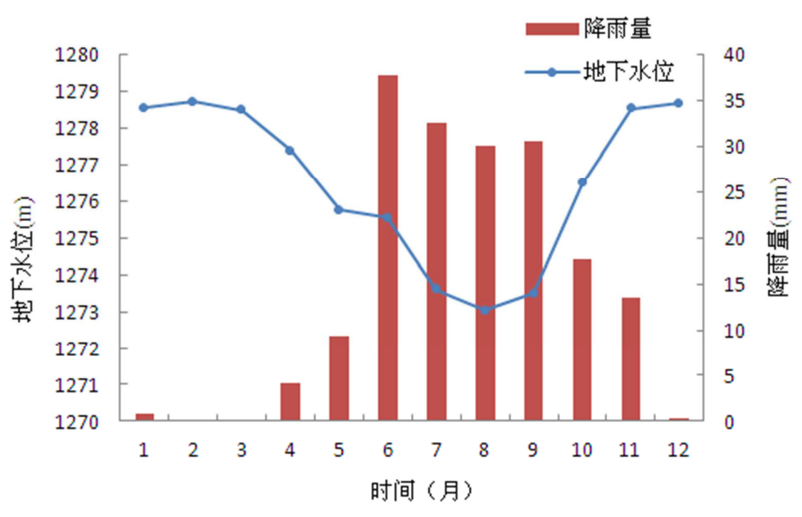

图3 ZB-02观测井2011年地下水位与降雨量关系图。

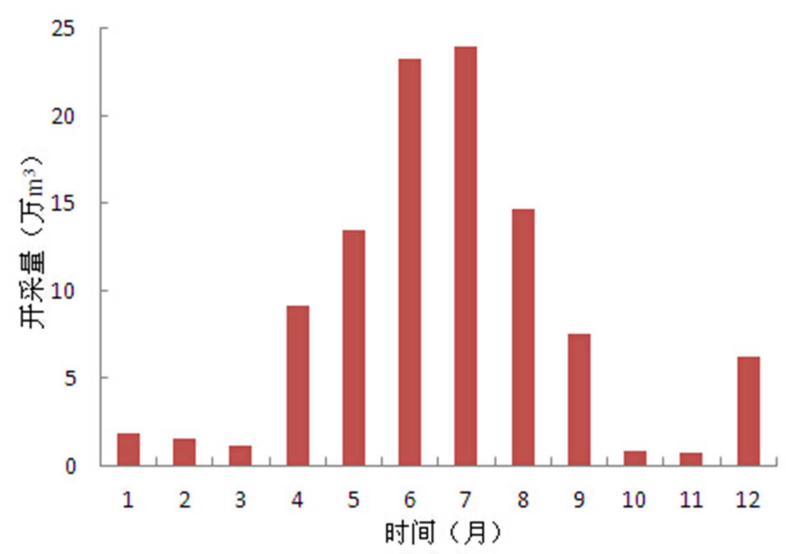

图4 ZB-02观测井2011年历月开采量柱状图。

图5为腰坝灌区1976 2014年地下水开采量历时曲线。 由图5可知腰坝灌区的年开采量总体趋势为逐年增多。 1976 1979年, 农业迅速兴起, 开采量急剧上升。1980 1989 年, 年开采量稳定在 2300 万 $\mathrm{m}^{3}$ 左右。1990 2010年地 下水开采量逐年增加, 致使2005年开采量达 4070 万 $\mathrm{m}^{3}$ 。 2010年后腰坝政府推行节水灌溉政策, 开采量有波动下降 趋势, 开采量由 2010 年的 4741.68 万 $\mathrm{m}^{3}$ 减少到 2014 年的 4219. 01 万的。

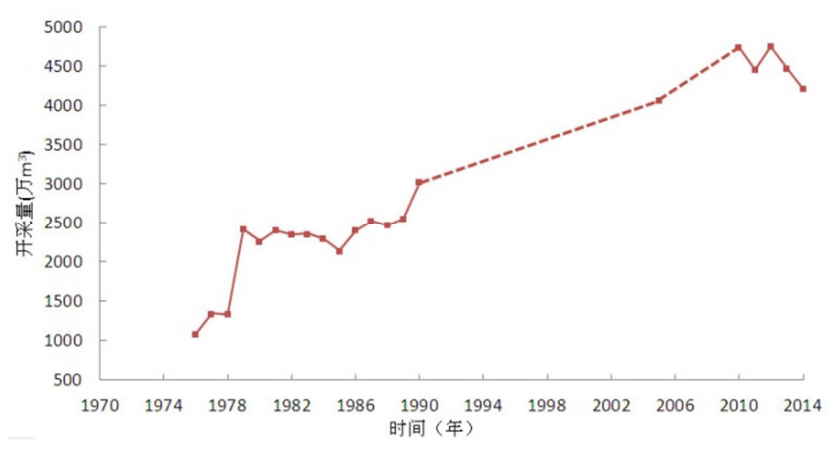

图5 腰坝灌区开采量历时曲线图。

图6为ZB-02观测井地下水位年际历时曲线。由图6可 知, 开采期与非开采期, 地下水位的年际变化趋势相同, 总趋势表现为持续下降。腰坝灌区开采量与地下水位的变 化趋势正好相反, 因此, 地下水位的高低主要取决于开采 量的大小。腰坝灌区作为开采量大于补给量的消耗型盆地
的一部分 ${ }^{[7]}$, 地下水位动态变化主要受当地人工开采的影 响, 地下水位动态类型为开采动态型。

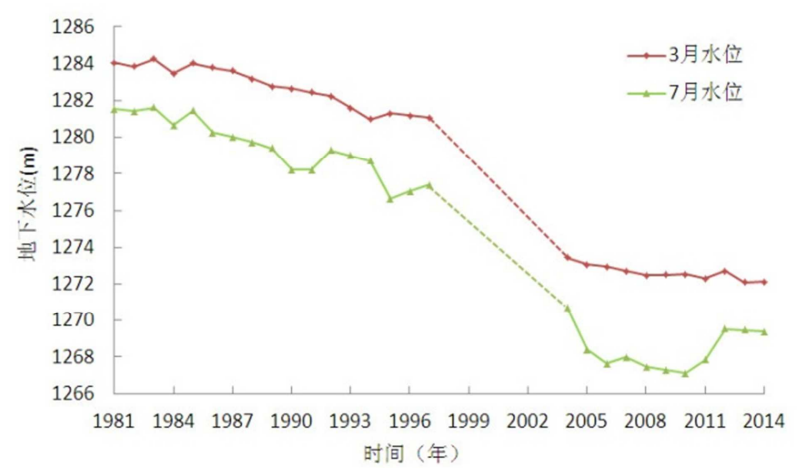

图6 ZB-02观测井3月和7月地下水位历时变化曲线图。

\section{4. 地下水位动态变化特征及降落漏斗的形成}

\section{1. 地下水位年内动态变化特征}

图7为腰坝灌区6口观测井2013年地下水位历时曲线。 6 口观测井的水位变化大致相同, 地下水位年内动态变化 特征总结为: 1 月 3 月中旬, 地下水位从前一年的冬灌后 开始回升。3月份的水位达到年内最高并趋于稳定。4月～ 8 月下旬, 是地下水开采强度最大的时段, 主要用于灌溉 玉米和小米, 此阶段灌区水位大幅度下降, 形成区域降落 漏斗, 观测水位为全年最低值, 变幅达 $2.56 \sim 6.38 \mathrm{~m}$ 。其 中， 4 月底 5 月底灌溉停歇，观测水位明显回升。8月下 旬 9月底, 开采地下水主要用于秋灌, 开采水量小。与 同年8月份相比, 水位有所回升。9月底 11月中旬, 灌区 停止抽水, 水位继续回升。11月中旬 12月上旬, 开采地 下水主要用于冬灌, 水位开始下降, 但下降幅度远小于7 月中旬, 停灌后水位开始恢复。

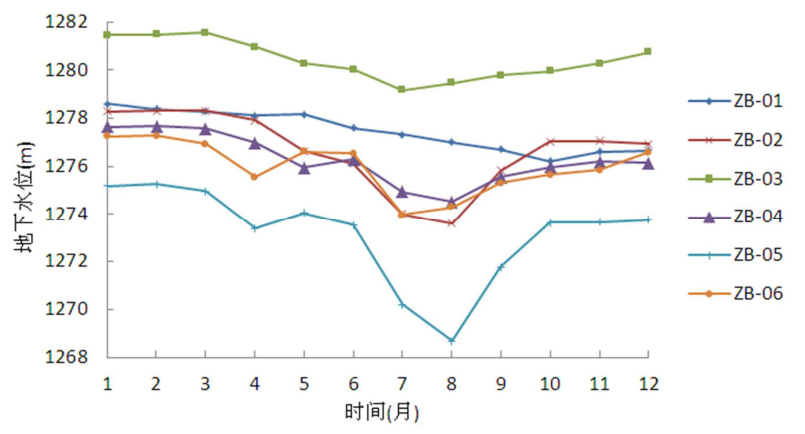

图7 腰坝灌区6口观测井2013年地下水位历时曲线图。

\section{2. 地下水位年际动态变化特征}

图8中的直方图表示当前一年与之前一年的地下水位 的差值, 当差值为正的时候表示水位回升; 反之, 水位下 降。在非开采期, ZB-02观测井地下水位在观测初期是波 动的, 1981 1986年地下水位为震荡式下降。1986 2008 年地下水位持续下降，且降幅速度不匀。在 2009 ～2014 年地下水位再次呈现震荡式下降。其他观测井的非开采期 地下水位动态见表 1 。 


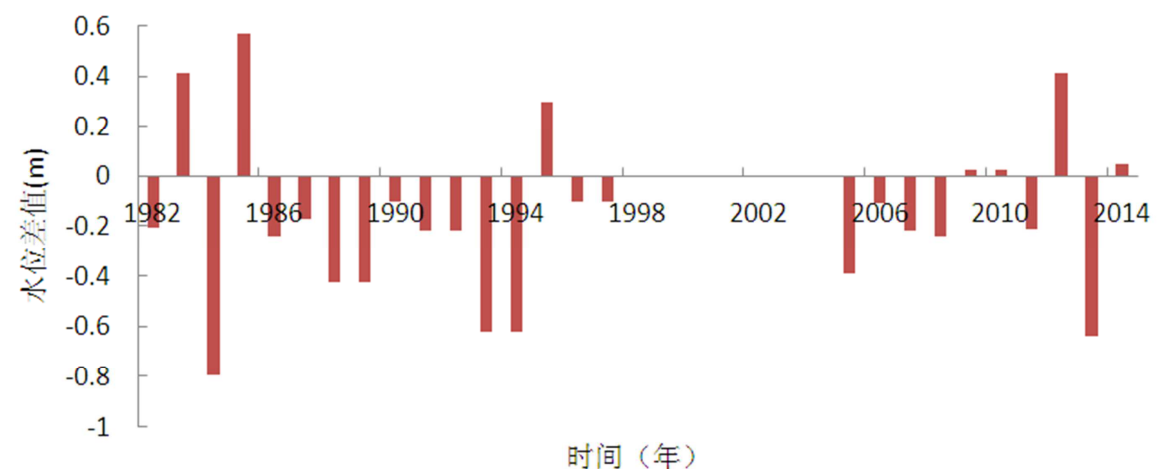

图8 ZB-02观测井1981 2014年3月水位差值变化图。

表1 腰坝绿洲6口观测井地下水位3月动态表。

\begin{tabular}{llllll}
\hline 观测年份 $(\mathrm{a})$ & 观测井 & 水位变化 $(\mathrm{m})$ & 水位降幅 $(\mathrm{m})$ & 年平均降幅 $(\mathrm{m} / \mathrm{a})$ & 井位 \\
\hline \multirow{5}{*}{$1980 \sim 1990$} & ZB-01 & $1284.64 \sim 1283.10$ & 1.544 & 0.1544 & 绿洲中部 \\
& ZB-04 & $1285.05 \sim 1282.54$ & 2.508 & 0.2508 & 绿洲西部 \\
& ZB-02 & $1284.06 \sim 1282.67$ & 1.385 & 0.1385 & 绿洲中部 \\
& ZB-03 & $1285.88 \sim 1284.13$ & 1.745 & 0.1745 & 绿洲中部 \\
& ZB-01 & $1283.10 \sim 1277.03$ & 6.064 & 0.3369 & 绿洲中部 \\
& ZB-02 & $1282.67 \sim 1272.49$ & 10.181 & 0.5656 & 绿洲中部 \\
& ZB-03 & $1284.13 \sim 1273.5$ & 10.631 & 0.5906 & 绿洲中部 \\
& ZB-01 & $1277.03 \sim 1276.82$ & 0.213 & 0.0355 & 绿洲中部 \\
& ZB-02 & $1272.49 \sim 1272.15$ & 0.340 & 0.0567 & 绿洲中部 \\
& ZB-03 & $1273.50 \sim 1274.03$ & -0.530 & -0.0883 & 绿洲中部 \\
& ZB-04 & $1291.82 \sim 1290.73$ & 1.090 & 0.1810 & 绿洲西部 \\
& ZB-05 & $1282.60 \sim 1281.97$ & 0.630 & 0.1050 & 绿洲南部 \\
& ZB-06 & $1276.77 \sim 1276.28$ & 0.490 & 0.0817 & 绿洲南部 \\
\hline
\end{tabular}

由表1可知, 腰坝灌区其他观测井在非开采期呈现出 相同的规律。由图6可知, 开采期与非开采期的地下水位 年际变化趋势相同, 整体呈现为持续下降。腰坝灌区地下 水位年际变化分为三个阶段：1980～1990年，随着农业的 逐渐兴起，地下水位缓慢下降，十年间下降了 1.385 $2.508 \mathrm{~m}$ ，年均降幅0.1385 0.2508 m/a。1990 2008年, 大规模人口涌入腰坝地区, 耕种面积急剧增加, 地下水严 重超采, 水位下降了 6.064 10.631m, 年均降幅0.3369 $0.59060 \mathrm{~m} / \mathrm{a} ; 2009$ 年后, 随着政府、社会与当地群众对 水资源的重视以及节水灌溉政策的推行 ${ }^{[8]}$, 地下水资源的 利用状况得到改观，水位下降变缓，6年间下降了 0.213 $1.09 \mathrm{~m}$, 年均降幅 $0.0355 \sim 0.181 \mathrm{~m} / \mathrm{a}$, 且部分地区水位有 小幅度回升, ZB-03观测井从2008年的 $1273.5 \mathrm{~m}$ 恢复到 2014 年的 $1274.03 \mathrm{~m}$, 但仍低于历史正常地下水位值。

\section{3. 降落漏斗的形成与发展}

利用Surfer11软件绘制出地下水等水位线图 [9]。由 图9a、9b、9c可知, 腰坝灌区开采状态下的地下水位变化 比较复杂。漏斗区位于强开采地区, 腰坝东部形成的降落 漏斗在1985年就呈现维形。随着时间的推移, 地下水开采 量不断增加, 水位持续下降, 漏斗开始西移并逐渐扩大, 在 2008 年到达ZB-02观测井附近，漏斗中心水位由1985年 的 $1282.6 \mathrm{~m}$ 下降到 2008 年的 $1773 \mathrm{~m}$ 。2009年后, 在节水灌溉 等措施的影响下, 漏斗中心水位有所恢复, 由 2008 年的
$1773 \mathrm{~m}$ 回升到 2014 年的 $1777 \mathrm{~m}$ 。由图9c、9d可知, 开采期与 非开采期的降落漏斗形态大致相同, 但开采期漏斗半径比 非开采期有明显的扩大，且漏斗区的地下水位比非开采期 的低, 由 3 月份的 $1777 \mathrm{~m}$ 下降到 6 月底的 $1274 \mathrm{~m}$ 。

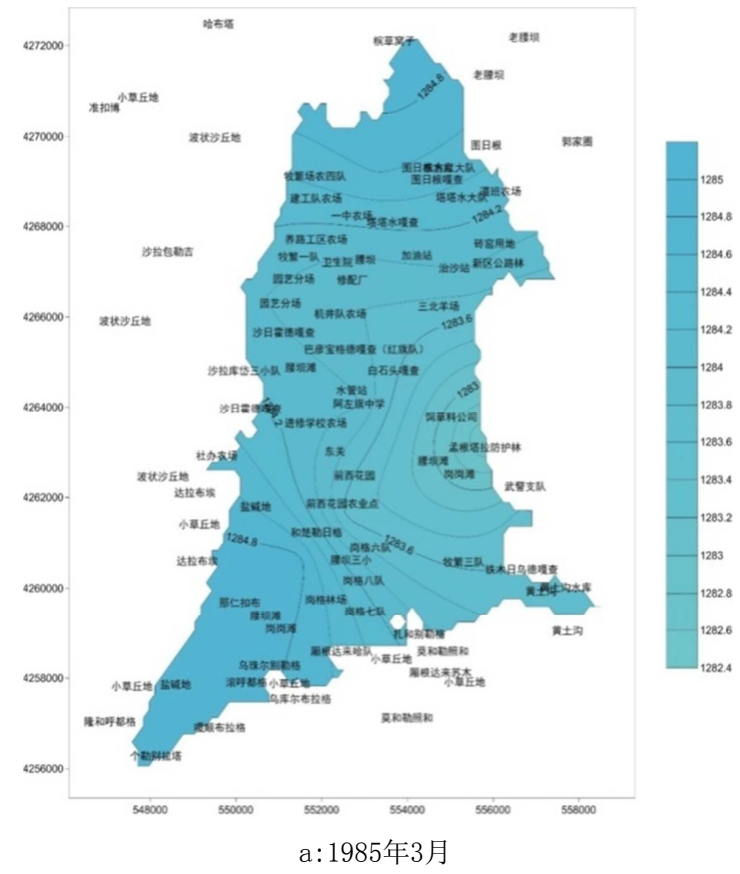




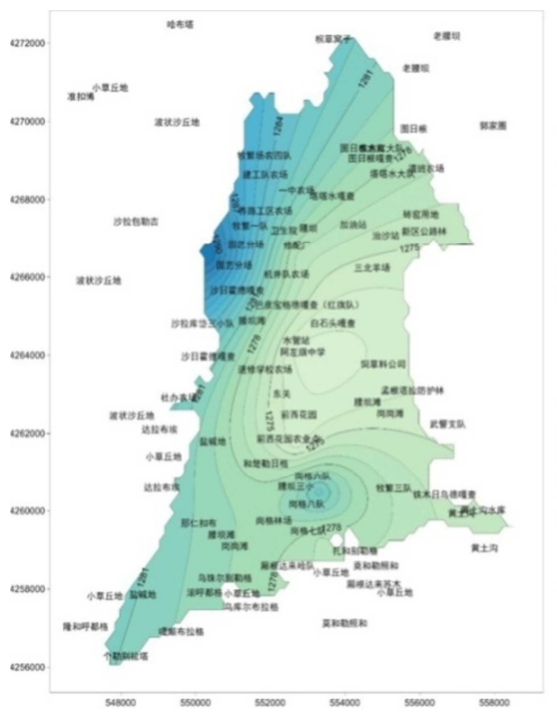

b:2008年3月
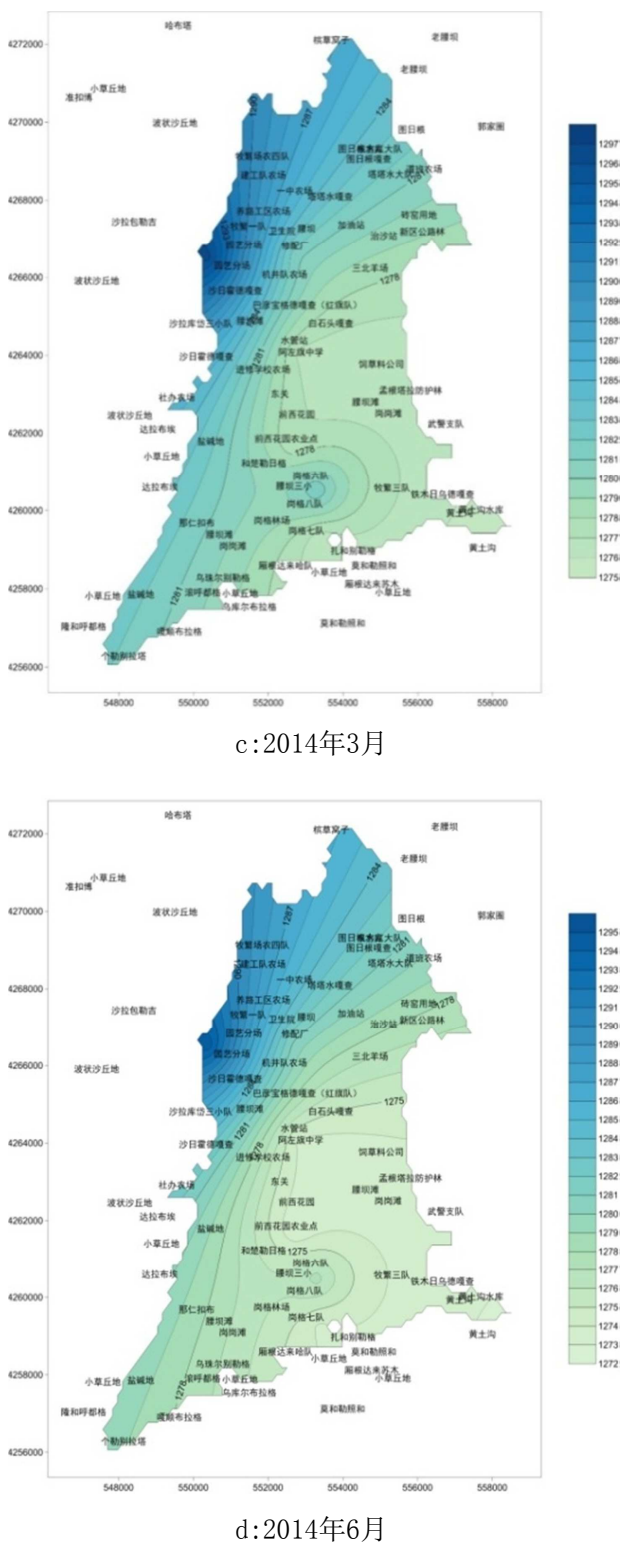

图9 腰坝灌区不同时间的地下水等水位线图。

\section{5. 地下水位动态成因分析}

腰坝灌区地下水位动态变化主要受开采量大小的影 响。补给地下水总量只有 2000 万 $\mathrm{m} 3 /$ 年左右, 但用水量每 年达 4000 万 $\mathrm{m} 3$ 以上, 近一半的用水来自于含水层的静储量。 造成地下水的超量开采的原因主要有: (1)种植结构不够合 理、农作物灌溉定额偏高。腰坝灌区种植结构以玉米、小 麦为主, 葵花、小米等为辅。玉米和小麦灌水量超过 600 $\mathrm{m} 3$ /亩, 远高于本地区玉米、小麦的实际生长需水量。(2) 灌溉方式粗放、灌溉设施老化且管理不完善。腰坝农田灌 溉多以大水漫灌方式, 大量消耗地下水资源。灌溉设施大 多是20世纪70 至80 年代修建的, 工程标准低且年久失修, 致使部分水量消耗于渠道渗漏。

\section{6. 结论}

利用腰坝绿洲1981 2014年的地下水位动态观测数 据, 分析地下水位年内、年际动态变化特征及影响因素, 得到以下结论: (1)腰坝灌区地下水位动态类型为人工开采 型, 开采地下水是影响地下水动态变化的主要因素。(2)4 月 8月为集中抽水期, 是地下水开采强度最大的时段, 灌区水位大面积下降, 形成区域降落漏斗。(3)开采期与非 开采期地下水位的年际变化趋势相同, 整体表现为持续下 降。(4)与腰坝绿洲地下水历史最低水位相比, 现阶段水位 有所恢复, 但仍处于严重超采阶段。腰坝地区应合理控制 地下水开采量, 以实现绿洲的可持续发展。

\section{参考文献}

[1] 李燕, 卢玉东, 李鸿娟, 等. 腰坝绿洲地下水位动态特征及对 植被变化影响 [J]. 地下水, 2012, 04:74-76。

[2] 姜凌, 李佩成, 胡安炎, 等. 内蒙古阿拉善腰坝绿洲地下水水 化学特征 [J]. 干旱区资源与环境, 2009, 11:105-110。

[3] 杨霞, 徐景春, 张武文. 生态农业技术在腰坝绿洲建设中的 应用 $[\mathrm{J}]$. 内蒙古农业大学学报 (自然科学 版), 2007, 02:98-101+153。

[4] 姜凌, 李佩成, 郭建青. 贺兰山西麓典型干旱区绿洲地下水 水化学特征与演变规律 [J]. 地球科学与环境学 报, 2009, 03:285-290。

[5] 李锦秀, 肖洪浪, 任娟. 阿拉善地区水资源与生态环境变化 及其对策研究 [J]. 干旱区资源与环境, 2010, 11:56-61。

[6] 张人权, 梁杏, 勒孟贵, 等. 水文地质学基础 [M]. 地质出版 社, 2011, 06:101-108。

[7] 杜方红, 黄文浩. 阿拉善地区生态环境问题及探讨 [J]. 内蒙 古环境保护, 2005, 03:7-11。

[8] 张伟, 李方, 杨丽. 阿拉善左旗绿洲的重要作用及保护建议 $[\mathrm{J}]$. 内蒙古水利, 2013, 06:76-77。 
[9] Natalie Orlowski, Florian Lauer, Philipp Kraft. Linking Spatial Patterns of Groundwater Table Dynamics and Streamflow Generation Processes in a Small Developed Catchment[J]. Water, 2014, $06(10)$ : 3085-3117.
[10] Fan Y, Li H, Miguez-Macho G. Global Patterns of Groundwater Table Depth [J]. The Scientific Monthly, 2013, 339 (6122) : 940-943. 